\title{
Mesenchymal Chondrosarcoma of Bone
}

National Cancer Institute

\section{Source}

National Cancer Institute. Mesenchymal Chondrosarcoma of Bone. NCI Thesaurus.

Code C53493.

A morphologic variant of chondrosarcoma arising from the bone. It is characterized by the presence of malignant small round cells, biphasic growth pattern, and well differentiated hyaline cartilage. Clinical presentation includes pain and swelling. The clinical course is aggressive, with local recurrences and distant metastases. 